\title{
Demographic, Socio-economic, and Regional Fertility Differentials in Pakistan
}

\author{
ABDUl HAKIM
}

\section{INTRODUCTION}

Pakistan, with an estimated population of 135.6 million in 1999 , is the seventh most populous country in the world. The historical trends indicate a continuous and exponentially increasing growth in population because of sustained high fertility and declining mortality. Currently, the population is growing at around 2.3 percent per annum, one of the highest rates of growth in the world. In Pakistan, the contraceptive prevalence is still low (24 percent) and fertility level (TFR 5.0) is among the highest in the world. There has been only a marginal decline in fertility in Pakistan over the last two and half decades. An average married woman in Pakistan still experiences a total of at least seven children if she survives and completes her reproductive periods.

The purpose of this analysis using data from a nationally representative sample survey, Pakistan Fertility and Family Planning Survey 1996-97 [see Hakim et al. (1998) for details] is to determine whether there are any differentials in fertility levels by age at marriage, educational level, occupation, region of residence (province), place of residence (urban or rural) and economic class. Both bivariate and multivariate analyses have been undertaken to examine the effect of the selected demographic and socio-economic variables on the level of fertility. Some variations by use of contraception, exposure to mass media, mother tongue, women's mobility and decision-making variables were also studied, but subsequently dropped because differentials were either not sustained or captured by other variables.

\section{METHOD OF ANALYSIS}

Fertility is affected by a number of interrelated factors in Pakistan. The examination of the bivariate relationships between selected demographic and socioeconomic variables with fertility is important. However, the reproductive behaviour 
in human population is the result of a complex web of socio-economic, biological and behavioural factors in which the factors themselves are intricately related to one another. Thus, to identify the effect of any particular factor on fertility, it is necessary to have control for others. Although the traditional approach is through crossclassification of the data, such analysis can handle only two or three variables at a time. Intricate interactive links between the independent variables and a dependent variable in the study of human behaviour, such as fertility, thus necessitate application of multivariate analysis techniques. Therefore, besides bivariate analysis, the net effect of each predictor variable on the dependent variable after controlling for the effect of other predictors and covariate has also been measured through mutlivariate analysis.

Given the type of data in the survey, the technique of Multiple Classification Analysis (MCA), which is analogous to multiple regression analysis with 'dummy variables', has been selected here to determine the net effect of each factor. Multiple Classification Analysis is a multivariate technique for examining the interrelationships between several predictor variables and a dependent variable within the context of an additive model. This technique has some distinct advantages as it can be used when the dependent variable is interval-scaled or even if it is a dichotomous variable and is not greatly skewed. Some other multivariate techniques can also be used with either interval scaled or dichotomous dependent variables, but the major advantage of MCA over other multivariate techniques is that it can incorporate predictor variables which are interval, ordinal or nominal scaled. MCA deals not only with linear but also non-linear relationships among predictors and the dependent variables [Andrews et al. (1973), pp. 1-8]. The MCA model assumes that the dependent variable is predicted by the additive effect of the predictors and can be expressed by the following equation:

$$
Y_{i j \ldots . n}=\bar{Y}+a_{i}+b_{j+\ldots \ldots \ldots \ldots .+} e_{i j \ldots . n}
$$

Where:

$Y_{i j \ldots . . n}$ is the score of individual $n$ who falls in the $i$-th category of predictor A, the $j$-th category of predictor $B$. etc.;

$\bar{Y}$ is grand mean on the dependent variable;

$a_{J}$ is the effect of memberships in the category of predictor $A$;

$b_{J}$ is the effect of memberships in the category of predictor $B$; and

$e_{i j \ldots . . .}$ is an error term.

Various statistics are computed through the MCA programme. The mean value for each category is calculated with deviations of each category from the grand mean before and after adjusting for other predictors and covariate. The eta statistic is the correlation ratio and indicates the proportion of the total sum of squares explained by the predictor. The beta or partial correlation ratio is the coefficient 
obtained after controlling for the effect firstly of the predictors, and then of the predictors plus the covariate. The multiple $R$ provides a summary estimate of the overall relationship between predictors and the dependent variable, adjusted for the degree of freedom. The multiple $R$ when squared measures the total variation in the dependent variable explained by all the predictors and covariate taken together, adjusted for degree of freedom.

\section{RESULTS AND DISCUSSION}

The detailed bivariate analysis has been carried out to see differentials in fertility by demographic and socio-economic variables (Tables 1-3). Table 4 contains the results of the Multiple Classification Analysis (MCA) and show the effect of predictor variables on children ever born. Selection of predictors and covariate is mainly on the basis of differentials observed in the bivariate analysis and other requirements of the analysis, such as significance levels and interactions.

The findings from the multiple $R$-squared value indicate that the variation explained by all the independent variables was low (Table 4). Only nine percent of the variance was explained by the seven predictors (age at marriage, education of woman and husband, occupation of husband, region and place of residence and economic class). The $R$-squared value increased substantially with the additive effect of all the predictors and the covariate age, when it explained 58 percent of the variance. Among the predictors, the beta values indicate that education of woman is the most significant variable followed by age at marriage, husband's education, place of residence, husband's occupation, region of residence and economic class. It is evident that, of the demographic variables, age and age at marriage are the most important determinants of fertility in Pakistan. Among the socio-economic variables, the educational level of both husband and wife are significant and important determinants of fertility in Pakistan. The individual effect of predictors, as gross effect, and adjusted effect after controlling for the effects of other predictors and covariate upon the dependent variable, children ever born, varies. The findings of both bivariate and multivariate analysis are discussed in the following paragraphs.

\section{Age at Marriage and Fertility}

In Pakistan, where contraception is not widely used, the length of reproductive period becomes the major determinant of the level of fertility. Age at marriage not only marks the entry into a sexual union and the beginning of exposure to child bearing but may also be an important gauge of women's status, since the older the woman is when she marries, the greater the likelihood that she has attended school or been employed, and the greater her chances of having a more equal relationship with her husband [Kazi and Sathar (1986), p. 602]. If age at marriage is early, a woman will have a longer exposure period and is expected to end up with higher fertility, while late marriage has been found to have a fertility reducing effect [Coale (1975)]. 
Table 1

Mean Number of Children Ever Born to Currently Married Woman Aged 15-49 by Demographic and Socio-economic Variables in Pakistan 1996-97

\begin{tabular}{|c|c|c|c|c|}
\hline Variables & $\begin{array}{c}\text { Unstandardised } \\
(15-49)\end{array}$ & $\begin{array}{c}\text { Standardised by } \\
\text { Age (15-49) }\end{array}$ & $\begin{array}{c}\text { Average Parity } \\
(45-49)\end{array}$ & Number \\
\hline \multicolumn{5}{|l|}{ Age at Marriage } \\
\hline$<15$ & 5.23 & 5.74 & 9.75 & 660 \\
\hline $15-19$ & 4.48 & 4.69 & 7.92 & 4466 \\
\hline $20-24$ & 3.50 & 3.22 & 6.61 & 1960 \\
\hline $25 \&+$ & 2.92 & 1.45 & 4.49 & 499 \\
\hline \multicolumn{5}{|l|}{ Education Level of Woman } \\
\hline No Education & 4.54 & 4.56 & 7.88 & 4085 \\
\hline Only Informal or Quranic & 4.52 & 4.20 & 7.66 & 1587 \\
\hline Upto Primary & 3.51 & 3.83 & 6.37 & 810 \\
\hline Upto Middle & 3.36 & 3.64 & 8.52 & 327 \\
\hline Upto Secondary & 2.91 & 3.22 & 5.42 & 350 \\
\hline Above Secondary & 2.52 & 2.51 & 3.60 & 425 \\
\hline \multicolumn{5}{|l|}{ Education Level of Husband } \\
\hline No Education & 4.78 & 4.68 & 7.98 & 2842 \\
\hline Only Informal or Quranic & 4.37 & 4.10 & 7.08 & 304 \\
\hline Upto Primary & 4.17 & 4.29 & 7.89 & 1173 \\
\hline Upto Middle & 4.02 & 4.20 & 7.43 & 927 \\
\hline Upto Secondary & 3.77 & 3.73 & 6.78 & 1352 \\
\hline Above Secondary & 3.17 & 3.33 & 5.41 & 984 \\
\hline \multicolumn{5}{|l|}{ Woman's Occupation } \\
\hline Professional & 3.59 & 2.75 & 3.63 & 133 \\
\hline Admn/Clerical/Sales & 4.54 & 4.98 & 0.0 & 27 \\
\hline Service & 4.51 & 4.63 & 7.66 & 387 \\
\hline Agriculture & 4.27 & 4.31 & 7.18 & 407 \\
\hline Production & 4.52 & 4.33 & 7.82 & 411 \\
\hline Other & 5.84 & 4.94 & 8.35 & 91 \\
\hline Not Currently Working & 4.13 & 4.16 & 7.58 & 6127 \\
\hline \multicolumn{5}{|l|}{ Husband's Occupation } \\
\hline Professional & 3.92 & 3.65 & 6.88 & 611 \\
\hline Administrative & 3.46 & 3.15 & 6.85 & 104 \\
\hline Clerical & 3.73 & 3.66 & 6.41 & 391 \\
\hline Sales & 4.36 & 4.16 & 7.77 & 857 \\
\hline Service & 4.39 & 4.51 & 8.50 & 514 \\
\hline Agriculture & 4.55 & 4.43 & 7.74 & 2104 \\
\hline Production & 3.95 & 4.20 & 6.66 & 1279 \\
\hline Transport & 4.11 & 4.36 & 7.87 & 510 \\
\hline Other & 3.98 & 4.11 & 7.49 & 1213 \\
\hline \multicolumn{5}{|l|}{ Place of Residence } \\
\hline Total Urban & 4.10 & 4.08 & 6.64 & 2245 \\
\hline Major Urban & 3.84 & 3.62 & 6.14 & 1235 \\
\hline Other Urban & 4.41 & 4.10 & 7.23 & 1009 \\
\hline Rural & 4.23 & 4.34 & 7.89 & 5339 \\
\hline \multicolumn{5}{|l|}{ Region of Residence } \\
\hline Punjab & 4.17 & 4.03 & 7.70 & 4429 \\
\hline Sindh & 3.98 & 4.10 & 6.52 & 1680 \\
\hline NWFP & 4.54 & 4.84 & 8.10 & 1102 \\
\hline Balochistan & 4.33 & 4.63 & 7.73 & 372 \\
\hline \multicolumn{5}{|l|}{ Economic of Class } \\
\hline Very poor & 4.31 & 4.47 & 7.82 & 2036 \\
\hline Poor & 4.34 & 4.39 & 7.83 & 3353 \\
\hline Lower Middle & 4.20 & 4.06 & 7.72 & 875 \\
\hline Upper Middle & 3.81 & 3.54 & 6.26 & 861 \\
\hline Upper & 3.18 & 2.94 & 5.31 & 460 \\
\hline Total & 4.19 & & 7.48 & 7584 \\
\hline
\end{tabular}

Source: PFFPS 1996-97, original analysis of data. 
Table 2

Mean Number of Children Ever Born to Currently Married Women Aged 15-49 by Education Level of Woman and Husband, Pakistan, 1996-97

\begin{tabular}{|c|c|c|c|c|c|c|c|}
\hline \multirow[b]{2}{*}{$\begin{array}{l}\text { Education } \\
\text { Level of } \\
\text { Husband }\end{array}$} & \multicolumn{6}{|c|}{ Education Level of Woman } & \multirow[b]{2}{*}{ Total } \\
\hline & $\begin{array}{c}\text { No } \\
\text { Education }\end{array}$ & $\begin{array}{c}\text { Only } \\
\text { Informal } \\
\text { or } \\
\text { Quranic }\end{array}$ & $\begin{array}{l}\text { Upto } \\
\text { Primary }\end{array}$ & $\begin{array}{l}\text { Upto } \\
\text { Middle }\end{array}$ & $\begin{array}{c}\text { Upto } \\
\text { Secondary }\end{array}$ & $\begin{array}{l}\text { Above } \\
\text { Secondary }\end{array}$ & \\
\hline No Education & 4.88 & 4.68 & 3.20 & 4.41 & 4.72 & 4.79 & 4.78 \\
\hline $\begin{array}{c}\text { Only Informal } \\
\text { or Qaranic }\end{array}$ & 4.52 & 4.56 & 2.84 & 1.26 & .00 & 1.00 & 4.37 \\
\hline Upto Primary & 4.32 & 4.48 & 3.54 & 3.37 & 2.59 & 2.00 & 4.17 \\
\hline Upto Middle & 4.20 & 4.50 & 4.03 & 2.97 & 2.04 & 1.92 & 4.02 \\
\hline $\begin{array}{l}\text { Upto } \\
\text { Secondary }\end{array}$ & 3.97 & 4.47 & 3.12 & 3.65 & 2.90 & 2.52 & 3.77 \\
\hline $\begin{array}{l}\text { Above } \\
\text { Secondary }\end{array}$ & 3.69 & 3.97 & 3.78 & 3.03 & 3.09 & 2.52 & 3.17 \\
\hline Total & 4.54 & 4.52 & 3.51 & 3.36 & 2.91 & 2.52 & 4.19 \\
\hline
\end{tabular}

Table 3

Mean Number of Children Ever Born to Currently Married Women Aged 15-49 by Region and Place of Residence, Pakistan, 1996-97

\begin{tabular}{lcccc}
\hline \multirow{2}{*}{ Region of Residence } & \multicolumn{3}{c}{ Place of Residence } & Total \\
\cline { 2 - 4 } Punjab & 4.12 & 4.33 & 4.14 & 4.17 \\
Sindh & 3.51 & 4.54 & 4.15 & 3.98 \\
NWFP & 4.34 & 4.56 & 4.56 & 4.54 \\
Balochistan & 3.54 & 4.68 & 4.32 & 4.33 \\
Total & $\mathbf{3 . 8 4}$ & $\mathbf{4 . 4 1}$ & $\mathbf{4 . 2 3}$ & $\mathbf{4 . 1 9}$ \\
\hline
\end{tabular}

Source: PFFPS 1996-97, original analysis of data. 
Table 4

Unadjusted and Adjusted Deviations from Grand Mean of Children Ever Born to Currently Married Women Aged 15-49, Pakistan 1996-97

\begin{tabular}{|c|c|c|c|c|}
\hline & $\begin{array}{r}\text { Unadjusted } \\
\text { ETA } \\
\end{array}$ & $\begin{array}{c}\text { Adjusted for } \\
\text { Predictors } \\
\text { BETA }\end{array}$ & $\begin{array}{r}\text { Adjusted for } \\
\text { Predictors/ } \\
\text { Covariate } \\
\text { BETA }\end{array}$ & Number \\
\hline Age at Marriage & .20 & .16 & .31 & \\
\hline$<15$ Years & 1.04 & .84 & 1.37 & 659 \\
\hline $15-19$ & .29 & .22 & .46 & 4431 \\
\hline $20-24$ & -.68 & -.50 & -.85 & 1942 \\
\hline $25+$ & -1.28 & -1.15 & -2.59 & 495 \\
\hline Woman's Education & .21 & .17 & .04 & \\
\hline No Education or only Informal & .35 & .29 & .07 & 5636 \\
\hline Primary or Middle & -.74 & -.61 & -.12 & 1125 \\
\hline Secondary or Above & -1.48 & -1.26 & -.34 & 766 \\
\hline Husband's Education & .17 & .10 & .05 & \\
\hline No Education or only Informal & .55 & .35 & .17 & 3132 \\
\hline Primary or Middle & -.09 & -.14 & -.02 & 2081 \\
\hline Secondary and Above & -.67 & -.34 & -.21 & 2315 \\
\hline Husband's Work Status & .07 & .06 & .01 & \\
\hline Professional & -.28 & .47 & .10 & 610 \\
\hline Other Services & -.12 & -.14 & -.01 & 4813 \\
\hline Agriculture & .35 & .18 & -.01 & 2104 \\
\hline Place of Residence & .05 & .11 & .00 & \\
\hline Major Urban & -.35 & .56 & -.02 & 1219 \\
\hline Other Urban & .22 & .50 & .02 & 1009 \\
\hline Rural & .04 & -.22 & .00 & 5298 \\
\hline Region of Residence & .06 & .05 & .05 & \\
\hline NWFP & .35 & .09 & .29 & 1102 \\
\hline Punjab & -.02 & .09 & -.08 & 4373 \\
\hline Sindh & -.21 & -.26 & -.07 & 1680 \\
\hline Balochistan & .14 & -.19 & .37 & 372 \\
\hline Economic Class & .10 & .02 & .05 & \\
\hline Lower & .12 & -.02 & .06 & 6226 \\
\hline Middle & -.36 & .17 & -.21 & 848 \\
\hline Upper & -1.05 & -.08 & -.45 & 453 \\
\hline $\begin{array}{l}\text { Multiple R. Squared (\%) } \\
\text { Grand Mean }\end{array}$ & 4.19 & 9.0 & 58.0 & \\
\hline
\end{tabular}

Source: PFFPS 1996-97, original analysis of data.

Note: Covariate used is age of women. $\mathrm{P}(\mathrm{F})$ ratio of all predictors significant at $<.001$ level.

Some authors have argued, however, that an increase in the age at marriage is not necessarily associated with lower fertility. A rise in age at marriage from under 15 years to $16-18$ years would produce an increase in fertility during the early years of marriage, and it may also raise fertility in the later years of married life insofar as postponement of marriage is favourable to the health of women and may exert its effect throughout the reproductive period. But the postponement of marriage beyond 19 years of age would probably produce an appreciable decline in fertility because 
women who marry at these ages will lose an appreciable amount of their fertile period and are not likely to compensate for the loss [Agarwala (1967)]. In Pakistani society, all Muslims, male and female, are supposed to marry and fulfill their sexual and procreative needs within marriage. Divorce, though allowed by religious prescription, is rare. Remarriage of widows and divorcees is also encouraged in Islam. A decline in fertility due to a rise in age at marriage has been documented in various studies in Pakistan [Alam and Karim (1986)]. In Pakistan the legal age at marriage for females is 16 years, yet many girls are married off below age 16. This is due to the religious and cultural beliefs of parents who often feel somewhat relieved after the marriage of their daughters.

It is evident from the findings of this study that age at marriage is inversely related to fertility in Pakistan (Table 1). The mean number of children ever born to women of all age groups whose age at marriage was less than 15 years was much higher than to those who married at age 15 years or over. For example, the mean number of children ever born was 5.2 for those who married below age 15 , whereas it was 4.5 for age at marriage 15-19, 3.5 for age at marriage 20-24 and 2.9 for those marrying at 25 years or above. Similarly, the average parity of women aged 45-49 years was 9.8 children for those who married under 15 years, compared to 7.9 children for those who married at ages 15-19 years, 6.6 children for those who married at ages 20-24 years and 4.5 children for those who married at age 25 years or above. A clear and consistent pattern indicating lower fertility with rising age at marriage is visible. This pattern also persists when controls for current age of women are introduced.

In the multivariate analysis, the effect of age at marriage as a predictor is the strongest. Its effect as eta and beta values remains significant (Table 4). Similarly differentials in mean number of children ever born also remain wide between younger and older groups of age at marriage. The contribution of other predictors could not diminish its effect and the findings of the bivariate analysis are upheld in this case.

\section{Education and Fertility}

There are numerous channels through which education can affect fertility. It is contended that education provides individuals with a new vision and normative orientation, better health care, better employment opportunities outside home, better knowledge of and access to family planning methods. These in turn, may produce a depressing effect on fertility [Cochrane (1979), p. 90]. Educational attainment alters parent's perceptions of the advantages of small families, brings changes in the status of women, changes the social and economic aspirations, and affects both attitude towards contraception and ability to understand and make use of particular methods [Cassen (1976), p. 90; Hakim and Salway (1999), pp. 17-20]. The empirical findings of a number of studies have supported such an inverse relationship between education and fertility [United Nations (1983), pp. 56-86]. 
The relationship between education and fertility, however, has not always been found to be an inverse one. In poor countries with relatively low levels of education and in the early phases of economic development, education may at first serve to raise fertility because of the association of education with improved health, lower levels of infertility, and shorter duration of breastfeeding [Ware (1981), p. 79]. Nevertheless, in the long run fertility declines with educational attainment because of the changes brought about by education, particularly attitudes towards family size. In fact, education is so intricately associated with many social, economic and psychological processes that the true nature of its relationship with fertility remains obscure [United Nations (1983), p. 84]. Education certainly affects age at marriage, and also affects other explanatory variables such as the attitude to ideal family size, and costs and benefits of children [Holsinger and Kasarda (1976), p. 154]. Cochrane (1979, pp. 6-9) has shown that the aggregate level of education in the community affects the level of fertility, and she also concluded that an inverse relation is much more consistent for female than male education.

Caldwell (1980, pp. 227-49) considered that the greatest impact of education is not direct but through the restructuring of family relationships and family economies and the effect of these on the direction of net wealth flows between generations. He believes that, fundamentally, schooling attacks the traditional family economic structure by weakening the authority of the old over the young and of the male over the female. Elaborating on this theme, Caldwell (1982) maintained that intergenerational cost and benefit shifts occur when parents begin to invest more in the education of their children than children contribute to the family through child labour and care for aged parents. This reversal in the intergenerational flow of wealth from that of children to parents to that of parents to children encourages couples to opt for smaller families. This theory of Caldwell fits in many situations. If parents provide their children with higher education it will lead to higher direct as well as indirect costs of having children.

The analysis of data for Pakistan shows a negative effect of education on fertility (Table 1). Women with no education have a higher mean number of children ever born compared to those with some formal education. The mean number of children ever born to women with no education is 4.5 , with primary education 3.5 , with secondary education 2.9 and with tertiary education 2.5. An increase in the level of education is associated with a decline in the number of children ever born. Even the age standardised mean number of children ever born reveals that fertility is lower for those women who have attained a higher level of education, compared to those who have less education or no education. Differentials are also clearly visible in the average parities for women in the age group 45-49 years, indicating 7.9 children ever born for those having no education, 6.4 with primary education, 5.4 with secondary and 3.6 with tertiary education. 
As compared to female education, male education does not indicate a strong inverse association with fertility (Table 1). No clear-cut differentials in fertility are noticeable between women whose husbands have no education and those having primary education. There is an indication of a weak but inverse relationship between husband's education and fertility, which is pronounced only with secondary or higher level of education. The average parity for women whose husbands have no education is 4.8 children; this remains at 4.2 children when husbands have primary education and only drops to 3.8 children when husbands have secondary education and to 3.2 children if husbands have tertiary education.

The effect of wife's education, while controlling for husband's education, remains more visible compared to the effect of husband's education (Table 2). When both wife and husband are educated, the inverse effect on fertility is more pronounced. With an increasing level of education for both partners, fertility declines considerably. For example, if both husband and wife have no education, the mean number of children ever born is 4.9. However, if both have a tertiary level of education, the mean number of children ever born is 2.5 indicating a 49 percent decline. A differential of almost similar magnitude existed and was documented in previous studies [Hakim (1994)].

In the multivariate analysis, as regards women's education, differentials noted in cross-classification analysis, remain large even when adjusted for other predictors. The effect of the covariate age reduces these differentials to some extent, but they still remain highly visible (Table 4). However, in regard to husband's education, differentials noted in bivariate analysis remain visible when adjusted for other predictors but its effect is less pronounced when adjusted for covariate age. This indicates the importance of education of women in Pakistani society for any change in reproductive behaviour. The education of men can be expected to affect fertility differently from the way fertility is affected by the education of women because of their different roles in the reproductive process and the different effects of education on their lives.

\section{Occupation and Fertility}

Although a negative association between female work and fertility has been found in several developed countries, the relationship has not always been clear and inverse in the case of developing countries [Shah (1986), p. 264]. In Pakistan, a few studies have examined the relationship between work participation of women and fertility. The findings of these studies indicate that women's work has not been found to have a consistent negative influence on fertility [Shah (1975); Syed (1978)]. Women's labour force participation in Pakistan is not necessarily associated with enhanced status [Sathar et al. (1988), p. 417]. However, women who work outside the home and particularly those who earn cash incomes are presumed to have enhanced control over household decisions, increased awareness of the world outside the home and subsequently more control over reproductive decisions. 
For a wife to work after marriage in Pakistan, she needs her husband's approval. It is thus conceivable that obtaining such permission depends upon several things, such as how conservative her husband is, what type of work she can perform, and how other persons (such as kin and neighbours) will react to her working outside the household. Moreover, employment opportunities outside the home are very limited for women. In the context of the position of women in the Pakistani society, where sex segregation and domination of males over females are common and women's work outside the home generally is not highly valued, it is usually assumed that working women, as a privileged group, would have lower fertility than their non-working counterparts. However, in this study, it has been found that, except for women working on professional positions, women working as salaried employees have rather slightly higher fertility than those who are either working for the family farms or perform home duties. Those women who work at home had the lowest average parity 4.1, compared to salaried employees (Table 1).

Professional women are usually better educated. In Pakistan uneducated women who are working outside their homes as salaried employees are presumably forced to take up paid employment as a necessity and their contribution to the household income is probably essential for their survival [Kazi and Sathar (1986), p. 605]. It seems that the category of working women in itself does not represent an effective determinant of fertility decline. Other factors, such as extended duration of breastfeeding, may be at work. Moreover, in Pakistan employment of women outside the home is not encouraged by the family and society. It is also likely that working women do not enjoy more freedom than their non-working counterparts in the decision-making processes of the family because of their subordinate position in the family.

A husband's occupation is a measure of social status in the community as well as the economic circumstances of the family. The occupation of the husband has been widely used as an index of socio-economic status in the study of fertility differentials. Classically, changes in the occupational distribution of the population of industrially advanced countries have accompanied a general decline in fertility. A relatively high fertility has been found to be associated with occupation in primary industries, particularly agriculture and mining, while lower fertility has been associated with the professional classes, white collar workers, and urban industrial workers [United Nations (1973), p. 100]. Information on the relationship between occupational status and fertility is very limited for high fertility countries. A review of the literature on males' occupation and fertility in many developing countries does not give a clear picture. The evidence suggests that other factors are more important than employment. In Pakistan, a male-dominated patriarchal Muslim society, male occupation is highly associated with the socio-economic status of the family. In particular, a woman's socio-economic status is determined by the occupation of her husband. Alam and Casterline (1984) found that husband's occupation in the modern 
sector was negatively related to fertility in Pakistan. Ahmad (1984, pp. 201-202) also confirmed that more men in professional and clerical groups in Pakistan use contraceptive methods than in other groups.

In this analysis, fertility differs to some extent by husband's occupation in Pakistan (Table 1). Women whose husbands work as salaried employees have comparatively lower fertility than those whose husbands are working in their own business or engaged in agriculture-related work. The multivariate analysis shows that the differentials observed for husband's occupational categories in the bivariate analysis for children ever born did not remain visible when adjusted for other predictors or the covariate age (Table 4).

\section{Region of Residence and Fertility}

Although Pakistani society is religiously homogeneous, with the majority of the population being followers of Islam, one of its features is the existence of a wide racial, linguistic, and cultural diversity in the population. Of all the defining features of 'ethnic groups', language and dialect are probably the most important. The present provincial divisions broadly identify these groups as Balochis, Pathans, Sindhis and Punjabis living in the four provinces of Pakistan, that is, Balochistan, North West Frontier Province (NWFP), Sindh and Punjab respectively. Pakistan's four provinces show considerable regional variation in population characteristics. Variations in fertility decline from 1960-1975 between the provinces have also been observed [Alam and Shah (1986), pp. 53-86].

This study finds moderate variations in fertility among different geographical areas of Pakistan (Table 1). The mean number of children ever born is highest in NWFP (4.5), followed by Balochistan (4.3), Punjab (4.2) and Sindh (4.0). The region of residence does not give rise to a wide range of differentials in fertility. In unadjusted categories, the mean number of children ever born is slightly higher in NWFP followed by Balochistan, Punjab and Sindh. In the multivariate analysis, when adjusted for other predictors and the covariate, this pattern in fertility is slightly changed, that is, a further reduction of fertility in Punjab and NWFP if other factors are controlled for, but an increase in Sindh and Balochistan (Table 4). This suggests that fertility is higher in Balochistan, followed by NWFP, Sindh and Punjab. It is evident that the fertility level in Punjab, which is the largest populated province of Pakistan (56 percent), is slightly lower than the national average when adjusted for other predictors or the covariate age. This also confirms the findings of earlier studies suggesting that in Pakistan, Punjab had the lowest fertility in both the 1960s and 1970s followed by Sindh and NWFP [United Nations (1987), p. 28].

\section{Place of Residence and Fertility}

The urban-rural differential in fertility is one of the most widely studied areas in fertility. It is generally expected that, in societies undergoing socio-economic, 
cultural, and demographic changes, fertility will be lower in urban than in rural areas due to the impact of a host of factors. The lower fertility in urban areas may be viewed from two perspectives. Firstly, at the aggregate (macro) level of analysis, urban fertility may be lower because the urban population has a larger proportion of couples who are well educated and have white collar jobs and who are thus likely to marry late and have smaller families. Secondly, at the individual (micro) level of analysis, one may hypothesise that the same level of education and income will produce lower fertility in urban than in rural areas due to the higher cost of raising the children in the urban setting. Moreover, the urban population contains a higher proportion of those who are expected to adopt new ideas and new life style first, and of those for whom a large family does not represent an economic benefit but rather a burden.

The difference between urban and rural fertility in Western European countries widened during the fertility decline, but narrowed during the period of recovery following the Second World War. But in some Eastern European countries and the USSR, the difference appeared to have widened during the 1950s. Results from the developing countries, on the other hand, do not show consistent differentials by urban-rural place of residence [United Nations (1973), p. 97]. Urban fertility was found to be lower than rural fertility in Taiwan [Freedman et al. (1972)] and Thailand [Goldstein (1973)], while higher urban than rural fertility was observed in Indonesia [University of Indonesia (1974)] and Egypt [Omran (1973)]. Analysis of World Fertility Survey data by Rodriguez and Cleland (1981) revealed that in all Latin American and Caribbean countries, urban fertility was lower than rural fertility, but the divergence in the reproductive behaviour of urban and rural populations in Asia and the Pacific was less pronounced.

According to [Davis (1951), pp. 70-71] in Pakistan and India as in other place the cities manifested lower levels of fertility than the countryside. However, in the 1961 census data of Pakistan, rural and urban fertility was virtually equal and Robinson (1967, p. 109) observed no apparent relationship between urbanisation and marital fertility in Pakistan. Hashmi (1965, p. 109) also argued that fertility in urban and rural areas did not exhibit any differentials, as he observed that in general the level of fertility in Karachi was by no means low. Karim (1974) also did not find any urbanrural fertility differentials in Pakistan. According to Yusaf and Rutherford (1981) both urban and rural fertility rates were in the neighbourhood of seven children with a slightly higher fertility in urban areas. However, Sathar (1979); Alam and Shah (1986); and Sathar and Casterline (1998) found that fertility was lower in urban areas of Pakistan. Whether this changing direction of the relationship between urbanisation and fertility is due to the difference in approaches or to a real trend needs to be examined.

In this study, place of residence does not reveal any significant difference in fertility (Table 1). The mean number of children ever born is marginally higher among other urban women (4.4), compared to their rural counterparts (4.2). 
However, mean number of children ever born is low among major urban women (3.8). The overall marginal difference between rural and other urban fertility does not exist when adjusted for the age of women. Nevertheless, it does look to the expected direction, that is, a slightly higher mean (4.3) for rural areas, followed by other urban (4.1) and major urban (3.6).

Analysis of the regional variations in rural and urban fertility in 1996-97 yield interesting results (Table 3). In Punjab and NWFP there is no appreciable difference between rural and urban fertility. In Balochistan and Sindh, clear differentials in fertility between rural and urban areas have been observed. In both regions the results are identical; that is, mean number of children ever born is much higher in other urban and rural areas compared to major urban. In Sindh the proportion of urban population is higher (around 50 percent) than other provinces of Pakistan. This segment of the population, mostly inhabited by the Urdu speaking ethnic group of Muhajirs (migrants), living in major urban cities is considered more educated and is well covered by health and family planning facilities. This finding for Sindh confirms the findings of some earlier researchers that fertility decline in certain urban areas of Pakistan, particularly in Karachi has begun [Sathar and Akhtar (1998); Sathar and Kazi (1990)].

Urban or rural place of residence has unexpected results in the case of fertility (CEB) in Pakistan compared with many other countries, with slightly higher fertility for other urban women. This differential in fertility has also been upheld in the multivariate analysis after controlling for the effects of other predictors and the covariant age (Table 4). It appears that there is not much difference in fertility between rural and urban areas in Pakistan. A possible reason could be that the visible onset of fertility decline in Pakistan has occurred in recent past, even in urban areas. In this case the findings in rural-urban fertility differences are not in the expected direction. It is possible that severe economic pressure associated with poor health and malnutrition is responsible to a large extent, for the lower fertility of the rural women in Pakistan. On the other hand, other urban women have also higher fertility because they can still afford to rear children because of their better income and the lower economic cost of educating the children. Moreover how far rural areas are away form the existing influence of urban areas is another important aspect. Contacts between rural and urban populations are more frequent.

Contrary to expectations the urban way of life seems to be positively associated with the level of fertility in Pakistani society. Although the urban dwellers are engaged in occupations mostly other than agriculture and household work, and are better educated than rural residents, their influence as a group is to a great extent limited by the fact they live in a society in which family interests continue to outweigh class identification and loyalty that probably cannot initiate a change in their reproductive behaviour. Even the position, role and power of urban women do not differ much from those of their rural counterparts. The basically unequal 
relationship between men and women remains constant in rural and urban areas. An urban woman has greater mobility but cannot challenge the superior social status of men. Hence urban centres in Pakistan differ from those of Western countries in their demographic response to urbanism.

Rural-urban migration has been a major contributing factor to high growth rate of urban population in Pakistan. Most male migrants leave their families behind in the rural areas, and maintain close ties with the rural areas through occasional visits. Thus, though they are physically members of urban population, they retain their rural values, norms and social interactions. Urbanism, therefore, probably failed to initiate change in the old (traditional) values, norms and behaviour favourable to uncontrolled child bearing. Moreover, many of those who are in the urban areas enjoy better social amenities in health and education, have stable and higher incomes, and thus probably can afford large number of children. Another possibility could be that most women in Pakistan still regulate their fertility mainly through prolonged breastfeeding, rather than through voluntary control, and the duration of breastfeeding is shorter in urban compared to rural areas.

\section{Economic Status and Fertility}

Household economic status of women also play an important role in fertility levels. For determining household economic status, households were given score for possessing household goods such as car, van, tractor, air conditioner, motorcycle, room cooler, telephone, refrigerator, television, washing machine, radio and bicycle. Women of upper class household economic status are likely to posses maximum and expensive household goods and have exposure to modern amenities and also likely to be better educated. For maintaining their standard they may prefer to have few children compared to women of lower economic class. Now under the economic pressure the over all perception of the people is changing as it is becoming difficult to afford large families of the past [Hakim and Miller (1996)] and it is more true for those who want modern amenities.

It is evident from the findings of this study that fertility differentials are pronounced among women of upper, middle and lower household economic status (Table 1). Fertility levels are much lower for women belonging to upper class (3.2), compared to lower class (4.3). These differentials have been upheld to a great extent even when adjusted for other predictors and covariate age (Tables 1 and 4).

\section{SUMMARY AND CONCLUSION}

Both, bivariate and multivariate analyses were undertaken to see the effect of factors influencing fertility in Pakistan. It was found that age is the most important variable explaining variance in fertility, with older women having higher fertility. After age, age at marriage was found to be another important demographic variable 
indicating lower fertility with rising age at marriage. In Pakistani society the significance of age in marital fertility is logical because of early and universal marriage and a low use of contraception by married couples. Therefore, as expected, the demographic variables of age and age at marriage are the most important determinants of fertility in Pakistan. The effect of age at marriage as a predictor is the strongest and the contribution of other socio-economic predictors did not diminish its effect .

The findings have also shown that an increase in education, particularly of women, can lead to a fertility decline. Women with no education have higher fertility, compared to those with some formal education. The inverse relationship between husband's education and fertility is only noticeable when husbands have at least a secondary level of education. Wide differentials noted in the bivariate analysis for woman's education remained even when adjusted for other predictors and covariate age. Differentials noted in the bivariate analysis for husband's education remained after adjusting for other predictors, but decreased to an almost negligible level when adjusted for age.

Even for employed women, education is an important factor for any change in reproductive behaviour. Differentials observed in the bivariate analysis for husbands' occupation level were not sustained when adjusted for other predictors and age.

Moderate variations in fertility were also found among the four provincial areas of Pakistan. In unadjusted categories, the mean children ever born was slightly higher in NWFP, followed by Balochistan, Punjab and Sindh. After adjustment for other factors in the multivariate analysis, this pattern in fertility was slightly changed, that is, the levels declined in Punjab and NWFP while they increased in Sindh and Balochistan. This suggests that the true level of fertility is highest in Balochistan, followed by NWFP, Sindh and Punjab.

In unadjusted categories, fertility levels were observed to be marginally higher among other urban women compared to their major urban and rural counterparts. However, fertility levels were comparatively lower in major urban areas. These differentials were not sustained when adjusted for other variables and there is not much difference in cumulative fertility between rural and urban areas of Pakistan.

Differentials in fertility levels have also been observed by household economic status of women. Fertility levels have been found much lower among upper economic class women, followed by middle and lower class women.

It appears from the analysis that the fertility transition has certainly started in Pakistan because variations in fertility levels have been found to some extent by urban and rural areas and in all regions of Pakistan, while the variation in decline is visible to a great extent by education level and household economic class of women. The policy implications of these findings are that there is need to accelerate education, in particular, education for females and refocus strategies of reproductive health and family planning programmes, ensuring maximum coverage and provision 
of services to high fertility level groups who are mostly uneducated, poor and living in rural and smaller urban towns.

\section{REFERENCES}

Agarwala (1967) Effect of a Rise in Female Marriage Age on Birth Rate in India. In proceedings of The World Population Conference 1965. United Nations, New York.

Ahmad, Sultan (1984) Fertility Differentials Among Selected Muslim Population: A Comparative Analysis. PhD Thesis, Department of Demography. Australian National University, Canberra.

Alam, Iqbal, and J. B. Casterline (1984) Socio-economic Differentials in Recent Fertility, WFS Comparative Studies: Cross National Summaries, Number 33. International Statistical Institute. Voorburg, Netherlands.

Alam, Iqbal, and Nasra M. Shah (1986) Population Composition, Mortality, and Fertility. In Nasra M. Shah (ed.) Pakistani Women: A Socioeconomic and Demographic Profile. Islamabad: Pakistan Institute of Development Economics, 53-86.

Alam, Iqbal, and Mehtab S. Karim (1986) Marriage Patterns, Martial Dissolution, and Remarriage. In Nasra M. Shah (ed.) Pakistani Women: A Socioeconomic and Demographic Profile. Islamabad: Pakistan Institute of Development Economics, 87-106.

Andrews, Frank M., James N. Morgan, John A. Songuist, and Laura Klem (1973) Multiple Classification Analysis. Ann Arbor: Institute for Social Research, University of Michigan.

Caldwell, J. C. (1980) Mass Education as Determinant of the Timing of Fertility Decline. Population and Development Review 6:1 225-255.

Caldwell, J. C. (1982) Theory of Fertility Decline. London: Academic Press.

Cassen, R. H. (1976) Population and Development: A Survey. World Development $4: 10 \& 11785-830$.

Coale, Ansley J. (1975) The Demographic Transition, the Population Debate: Dimensions and Perspectives. Papers of the World Population Conference, Bucharest, 1974. United Nations, New York 1: 347-355.

Cochrane, S. H. (1979) Fertility and Education. Baltimore: The John Hopkins University Press .

Davis, Kingsley (1951) The Population of India and Pakistan. New Jersey: Princeton University Press.

Freedman, R. I., C. Coombs, and Ming-Chen Chang (1972) Trends in Family Size Preferences and Practice of Family Planning, Taiwan, 1965-70. Studies in Family Planning 3:12 281-296.

Goldstein, Sydeny (1973) Interrelationships between Migration and Fertility in Thailand. Demography 10:2 225-241. 
Hakim, Abdul (1994) Factors Affecting Fertility in Pakistan. The Pakistan Development Preview 33:4 685-709

Hakim, Abdul, and Peter C. Miller (1996) Family Planning in Pakistan: Have We Reduced a Turning Point ? IUSSP Conference, Rawalpindi.

Hakim, Abdul, John Cleland, and Mansoor-ul-Hassan Bhatti (1998) Pakistan Fertility and Family Planning Survey 1996-97. Islamabad: National Institute of Population Studies.

Hakim, Abdul, and Sarah Salway (1999) Women's Autonomy and Uptake of Contraception in Pakistan. Islamabad: National Institute of Population Studies.

Hashmi, Sultan S. (1965) The People of Karachi: Demographic Characteristic. Pakistan Institute of Development Economics, Karachi.

Holsinger, D. B., and J. D. Kasarda (1976) Education and Human Fertility, Sociological Perspectives. In R. G. Ridker (ed.) Population and Development: The Search for Selective Interventions. Baltimore: Johns Hopkins University Press. 154-181.

Karim, Mehtab S. (1974) Fertility Differentials by Family Type. The Pakistan Development Review 13:2 129-144.

Kazi, Shehnaz, and Zeba A. Sathar (1986) Productive and Reproductive Choices: Report of a Pilot Survey of Urban Working Women in Karachi. The Pakistan Development Review 25:4 594-606.

Omran, A. R. (ed.) (1973) Egypt: Population Problems and Prospects. Carrolina: Chapel Hill Population Centre. University of North Carolina.

Population Welfare Division (1986) Pakistan Contraceptive Prevalence Survey 1984-85. Population Welfare Division, Islamabad.

Robinson, W. C. (1967) Differential Fertility in Pakistan. In W. C. Robinson (ed.) Studies in the Demography of Pakistan. Karachi: Pakistan Institute of Development Economics. 99-130.

Rodriguez, German, and John Cleland (1981) Socio-economic Determinants of Fertility in Twenty Countries: A Multivariate Analysis. In World Fertility Survey Conference 1980 held at London, Record of Proceedings, International Statistical Institute. Voorburg, Netherlands. 2: 337-434.

Sathar, Zeba A. (1979) Rural Urban Fertility Differentials in Pakistan: 1975. The Pakistan Development Review 18:3 231-251.

Sathar, Zeba A., and Afifa Akhtar (1988) Evidence of Fertility Decline in Karachi. The Pakistan Development Review 27:4 659-668.

Sathar, Zeba A., and John B. Casterline (1998) The Onset of Fertility Transition in Pakistan. Population and Development Review 24:4 773-796.

Sathar, Zeba A., N. Crook, C. Callum, and S. Kazi (1988) Women's Status and Fertility Change in Pakistan. Population and Development Review 14:3 415-422.

Sathar, Zeba A., and Shahnaz Kazi (1990) Women, Work and Reproduction in Karachi. International Family Planning Perspectives 16:2 66-80. 
Shah, Nasra M. (1975) Female Labour Force Participation and Fertility Desire in Pakistan: An Empirical Investigation. The Pakistan Development Review 14:2 185-206.

Shah, Nasra M. (1986) Female Employment: Trends, Structure, Utilisation, and Constraints. In Nasra M. Shah (ed.) Pakistani Women: A Socioeconomic and Demographic Profile. Islamabad: Pakistan Institute of Development Economics. 264-301.

Syed, Sabiha Hassan (1978) Female Status and Fertility in Pakistan. The Pakistan Development Review 17:4 408-430.

University of Indonesia (1974) Indonesian Fertility-Morality Survey, 1973: Preliminary Report, Java, Jakarta (Mimeographed).

United Nations (1973) The Determinants and Consequences of Population Trends: New Summary of Findings on Interaction of Demographic, Economic and Social Factors, Volume I. New York: Department of Economic and Social Affairs. (Population Studies, Number 50).

United Nations (1983) Relationship between Fertility and Education: A Comparative Analysis of FWS Data for Twenty Two Developing Countries. New York: United Nations.

United Nations (1987) Levels and Trends of Fertility for Small Geographical Areas in Pakistan Using census Data, Bangkok: ESCAP. (Asian Studies No. 62-1).

Ware, Helen (1981) Fertility and Status of Women. In Women, Demography and Development, Demography Teaching Notes 3. Canberra: Development Studies Centre, Australian National University.

Yousaf, Farhat, and D. Retherford (1981) Urban-Rural Fertility Differences in Pakistan. Journal of Social Sciences 13: 491-499. 